\title{
Epileptic seizure after treatment with thiocolchicoside
}

This article was published in the following Dove Press journal:

Therapeutics and Clinical Risk Management

6 August 2009

Number of times this article has been viewed

\author{
Pedro Giavina-Bianchi ${ }^{1,2}$ \\ Mara Giavina-Bianchi' \\ Luciana Kase Tanno' \\ Luis Felipe Chiaverini Ensina' \\ Antôno Abílio Motta' \\ Jorge Kalil ${ }^{1,2}$ \\ 'Division of Clinical Immunology \\ and Allergy, University of São Paulo, \\ São Paulo, SP, Brazil; ${ }^{2}$ Institute \\ of Science, Hospital Alemao \\ Oswaldo Cruz
}

Correspondence: Pedro Giavina-Bianchi

R. Prof. Artur Ramos 178 ap.2I IA,

Zip Code: 01454-904, São Paulo,

SP, Brazil

Email saudesos@terra.com.br
Background: Adverse drug reactions are important determinants of inpatient and outpatient morbidity. Thiocolchicoside is a semisynthetic derivate of naturally occurring colchicoside, which is largely used in humans as a centrally acting muscle relaxant. Epileptic seizures after thiocolchicoside intake have been reported in individuals with a history of epilepsy, acute brain injury or possible blood-brain barrier disruption.

Case report: We report the case of a 66-year-old male patient presenting a sudden epileptic seizure temporally related to the intake of thiocolchicoside for muscle contracture and pain. The probably causes of the seizures were thiocolchicoside intake and cerebral microhemorrhages attributed to cerebral amyloid angiopathy.

Discussion: Drugs only rarely cause focal seizures. Our case indicates that thiocolchicoside can precipitate seizures in predisposed patients, and that its use should be avoided in patients with brain diseases (and therefore lower seizure thresholds) or blood-brain barrier disruption. This information should be provided in the drug package insert.

Keywords: adverse drug reaction, thiocolchicoside, coltrax, epileptic seizure, muscle relaxant, cerebral amyloid angiopathy

\section{Background}

Adverse drug reactions are defined as noxious, unintended or undesired effects of any drug used for prophylaxis, diagnosis or therapy. Such effects constitute an important determinant of inpatient and outpatient morbidity. According to the drug package insert, the main adverse effects of thiocolchicoside (Coltrax ${ }^{\circledR}$; AventisPharma) are nausea, somnolence, asthenia, allergy and vasovagal reaction. It is contraindicated in patient with history of drug allergy or vasovagal reaction during previous utilization. ${ }^{1}$

Thiocolchicoside is a semisynthetic derivate of naturally occurring colchicoside, which is largely used in humans as a centrally acting muscle relaxant. This compound also has anti-inflammatory and analgesic effects. It is an analogue of colchicine, since they share the same benzo(alpha)heptalenic moiety. ${ }^{2}$

The experimental use of colchicine has been shown to induce epileptic foci in rats, causing generalized seizures and death. ${ }^{3-5}$ The epileptogenic activity of thiocolchicoside occurs mainly when there are minimal lesions of the dura and arachnoid membranes. ${ }^{5}$ Epileptic seizures in humans have also been reported in patients with a history of epilepsy, acute brain injury or possible blood-brain barrier disruption. ${ }^{6}$

Here, we report a case of sudden epileptic seizure temporally related to intake of thiocolchicoside for muscle contracture and pain. submit your manuscript $\mid$ www.dovepress.com

Dovepress 


\section{Case report}

A 66-year-old Caucasian man of Italian descent suddenly developed partial motor seizures of the right upper limb and face with speech arrest. There were three episodes of acute symptomatic seizures during a 12 -hour period. This occurred after intake of thiocolchicoside for 3 days $(4 \mathrm{mg}$ bid, in a total dose of $20 \mathrm{mg}$ ), as prescribed for muscular contracture and pain. Seizures began 6 hours after the final dose.

He had presented one episode of severe headache 6 months earlier, which had been investigated using computed tomography (CT), magnetic resonance imaging (MRI) and cerebrospinal fluid examination, all of which produced normal results.

As co-morbidity, he had been suffering from diabetes mellitus, controlled with metformin ( $850 \mathrm{mg}$ bid), for 10 years. He had no history of epileptic seizures.

The results of the neurological examination were normal.

The thiocolchicoside was discontinued, and phenytoin anticonvulsive therapy was instituted. The seizures were thus controlled, and there were no further episodes.

An additional MRI scan was ordered. The new scan revealed three areas of microhemorrhage in the left frontal, right frontal and left occipital lobes, the last presenting local signs of gadolinium enhancement. We reviewed the MRI scan taken 6 months prior and observed that the microhemorrhages in the right frontal and left occipital lobes had been present at that time. A single photon emission computed tomography scan of the brain showed focal cortical hyperperfusion in left frontal lobe. Electroencephalography and angiography findings were normal.

The results of thorough laboratory testing (cell counts; glucose level; erythrocyte sedimentation rate; serum levels of protein, $\mathrm{Na}, \mathrm{K}, \mathrm{Ca}, \mathrm{Mg}, \mathrm{P}$, alanine aminotransferase, aspartate aminotransferase, gamma-glutamyl transpeptidase, alkaline phosphatase and bilirubin; coagulation tests; creatine kinase level; urea nitrogen level; creatinine level; autoantibody titers; complement activation; and urine exam) were normal.

Cerebral microhemorrhages were imputed to cerebral amyloid angiopathy (CAA), ${ }^{7}$ which, together with the thiocolchicoside treatment, constituted the probably cause of the seizures.

Phenytoin had to be changed to oxcarbazepine due to an elevation in liver enzyme levels. Anticonvulsive therapy was maintained for 6 months and then discontinued. At 9 months after the initial episode, the patient was not taking anticonvulsive drugs and had not experienced any additional seizures.

\section{Discussion}

This is the fourth case reported in the literature in which a relationship between seizures and thiocolchicoside was demonstrated. ${ }^{6}$ The three other cases occurred in Italy (our patient was of Italian descent), and this is the second case in which there was no history of seizures. In the two cases in which there was a history of epilepsy, the patients had been seizure-free for 7 and 9 years, respectively, and presented disease exacerbations only after thiocolchicoside intake. The other case in which there was no such history was in a 40-year-old male patient who had been in a traffic accident and presented CT-proven cerebral contusion of the left hemisphere. Intramuscular thiocolchicoside was administered (4 mg bid). Approximately 30 minutes after the second daily injection, the patient had a generalized tonic-clonic seizure.

The mechanism of action of thiocolchicoside is only partially understood. Previous studies have suggested that it has an agonist interaction with spinal-strychnine-sensitive receptors that could mediate its myorelaxant effect, ${ }^{8}$ although such interaction does not readily explain how it might induce seizures. ${ }^{6}$ Another study demonstrated a pharmacological profile indicating a preferential interaction of this compound with a cortical subtype of the gamma-aminobutyric acid type $\mathrm{A}\left(\mathrm{GABA}_{\mathrm{A}}\right)$ receptor that expresses low-affinity binding sites for GABA. The low-affinity recognition site seems to be an antagonist-binding site, a finding that can readily explain the powerful convulsant effect of thiocolchicoside observed in some humans. ${ }^{6,9}$

The convulsant potential of thiocolchicoside is likely to involve an overwhelming effect of drug antagonism at a subset of $\mathrm{GABA}_{\mathrm{A}}$ receptors over the drug inhibitory effect of allosteric activation of strychnine-sensitive glycine receptors. ${ }^{5}$ Another study provided molecular evidence that the epileptogenic activity of thiocolchicoside might be due to inhibition of the function of inhibitory receptors in the central nervous system. ${ }^{10}$

Thiocolchicoside induced epileptic seizures and even death in rats that received this drug parentally, at the dosage of 6 to $12 \mathrm{mg} / \mathrm{kg}$, although only in rats that had minimal lesions of the dura and arachnoid membranes. ${ }^{5}$ Our patient weighed $80 \mathrm{~kg}$ and presented seizures when treated with a much lower dose $(0.25 \mathrm{mg} / \mathrm{kg}$ for the cumulative dose or $0.05 \mathrm{mg} / \mathrm{kg}$ for a single dose).

In our case, the patient had cerebral microhemorrhages, consistent with cerebral amyloid angiopathy (CAA), ${ }^{7}$ which 
accounts for the majority of primary lobar intracerebral hemorrhage in the elderly. ${ }^{11}$ The presence of multiple, strictly lobar hemorrhages (including microhemorrhages) detected in MRI sequences has been shown to be highly specific for severe CAA in elderly patients presenting no other definitive cause of intracerebral hemorrhage, such as trauma, ischemic stroke, tumor, hypertension, coagulopathy, excessive use of anticoagulants or vasculitis. ${ }^{12,13}$ Gradient-echo or $\mathrm{T} 2 *$-weighted MRI is a technique that is highly sensitive in the detection of old and recent cerebral hemorrhage. ${ }^{12,13}$ This test is capable of detecting millimeter-sized paramagnetic blood products (including hemosiderin) in the brain parenchyma. Since hemosiderin remains stored at sites of previous bleeding, hemorrhagic burden can be assessed over time.

For at least 6 months prior to the seizure, our patient had presented intracerebral microhemorrhages probably due to amyloid angiopathy. Thiocolchicoside might have lowered the seizure threshold and precipitated the acute symptomatic seizure.

Drugs only rarely cause focal seizures. Our case, as do the other three described before, indicates that thiocolchicoside can precipitate seizures in predisposed patients and should be avoided in patients with brain diseases (and therefore lower seizure thresholds) or blood-brain barrier disruption. This information should be included in the drug package insert.

\section{Disclosures}

The authors declare no conflicts of interest.

\section{References}

1. AventisPharma. Aventis Pasteur Ltda. [package insert] Coltrax ${ }^{\circledR}$ (thiocolchicoside). São Paulo, Brazil; 2008.

2. Janbroers JM. Review of the toxicology, pharmacodynamics and pharmacokinetics of thiocolchicoside, a GABA-agonist muscle relaxant with anti-inflammatory and analgesic actions. Acta Ther. 1987;13:221-227.

3. Reynolds AF, Oakley JC. The colchicines experimental epileptic focus: an intracellular study. Brain Res. 1984;322:326-328.

4. Wisniewski H, Terry RD. Experimental colchicines encephalopathy. Lab Invest. 1967;17:577-587.

5. Sechi GP, De Riu PL, Mameli O, Deiana GA, Cocco GA, Rosati G. Focal and secondarily generalized convulsive status epilepticus induced by thiocolchicoside in the rat. Seizure. 2003;12:508-515.

6. De Riu PL, Rosati G, Sotgiu S, Sechi GP. Epileptic seizures after treatment with thiocolchicoside. Epilepsia. 2001;42:1084-1086.

7. Viswanathan A, Chabriat H. Cerebral microhemorrhage. Stroke. 2006; 37:550-555.

8. Cimino M, Marini P, Cattabeni F. Interaction of thiocolchicoside with $[3 \mathrm{H}]$ thiocolchicoside binding sites in the rat brain and spinal cord. Neuropharmacology. 2001;40:1044-1049.

9. Balduini W, De Angelis V, Mazzoni E, Depoortere H, Cattabeni F, Cimino M. Autoradiographic localization of $[3 \mathrm{H}]$ thiocolchicoside binding sites in the rat brain and spinal cord. Neuropharmacology. 2001;40:1044-1049

10. Mascia MP, Bachis E, Obili N, et al. Thiocolchicoside inhibits the activity of various subtypes of recombinant $\mathrm{GABA}(\mathrm{A})$ receptors expressed in Xenopus laevis oocytes. Eur J Pharmacol. 2007;558: $37-42$.

11. O'Donnell HC, Rosand J, Knudsen KA, et al. Apolipoprotein e genotype and the risk of recurrent lobar intracerebral hemorrhage. $N$ Engl J Med. 2000;342:240-245.

12. Greenberg SM, O'Donnell HC, Schaefer PW, Kraft E. MRI detection of new hemorrhages: potential marker of progression in cerebral amyloid angiopathy. Neurology. 1999;53:1135-1138.

13. Knudsen KA, Rosand J, Karluk D, Greenberg SM. Clinical diagnosis of cerebral amyloid angiopathy: validation of the Boston criteria Neurology. 2001;56:537-539.
Therapeutics and Clinical Risk Management

\section{Publish your work in this journal}

Therapeutics and Clinical Risk Management is an international, peerreviewed journal of clinical therapeutics and risk management, focusing on concise rapid reporting of clinical studies in all therapeutic areas, outcomes, safety, and programs for the effective, safe, and sustained use of medicines. This journal is indexed on PubMed Central, CAS,

\section{Dovepress}

EMBase, Scopus and the Elsevier Bibliographic databases. The manuscript management system is completely online and includes a very quick and fair peer-review system, which is all easy to use. Visit http://www.dovepress.com/testimonials.php to read real quotes from published authors. 